\title{
Tribological Performance Evaluation of Hardwood Charcoal Powder Reinforced Polyester Resin with Response Surface Modelling and Optimization
}

\author{
F.O. Edoziuno ${ }^{a, b, *}$, R.O. Akaluziaa ${ }^{a}$ A.A. Adediran ${ }^{c, d *}$, B.U. Odonia, S. Edibo ${ }^{a}$, O.S. Adesina ${ }^{c, d}$ \\ ${ }^{a}$ Department of Metallurgical Engineering, Delta State Polytechnic, P.M.B. 1030 Ogwashi-Uku, Nigeria, \\ ${ }^{b}$ Department of Metallurgical \& Materials Engineering, Nnamdi Azikiwe University, P.M.B. 5025 Awka, Nigeria, \\ ${ }^{c}$ Department of Mechanical Engineering, Landmark University, Omu-Aran, Kwara State, Nigeria, \\ ${ }^{d}$ Landmark University SDGs-9 (Industry, Innovation and Infrastructure Research Group), Landmark University Omu- \\ Aran, P.M.B 1001, Kwara State, Nigeria.
}

Keywords:

Wood charcoal

Polyester

Polymer composite

Tribology

Dry sliding wear

Response surface modelling

\section{* Corresponding author: \\ Francis O. Edoziuno \\ E-mail: francisedoziuno@gmail.com}

Received: 30 September 2020

Revised: 16 November 2020

Accepted: 22 April 2021

\section{A B S T R A C T}

This work examined the tribological performance of hardwood charcoal powder reinforced polyester composites using experimental, response surface modelling and optimization techniques. Dry sliding wear characteristics (weight loss, volume loss, specific wear rate and wear resistance) of hardwood charcoal powder reinforced polyester composites were determined under the conditions of constant load, varying reinforcement particle sizes $(75,150,250 \& 300 \mu \mathrm{m})$ and concentrations (5, 10, 15, 20, 25 \& 30 wt\%). The developed composites exhibited slightly good wear properties at lower reinforcement content and larger particle sizes. Overall best wear properties compared to the unreinforced polyester were given by the $150 \mu \mathrm{m}$ particle size with a weight loss of $0.0002 \mathrm{~g}$, volume loss of $0.194 \mathrm{~mm}^{3}$, specific wear rate of $0.004 \mathrm{~mm}^{3} / \mathrm{Nm}$ and a markedly high wear resistance of 25, $257.73 \mathrm{~mm} / \mathrm{mm}^{3}$ at $5 w t \%$ reinforcement concentration. SEM morphology of the worn surface indicated the existence of strong interfacial interactions and bonding between charcoal particles and polyester resin with micro ploughing and cutting caused by progressive sliding of the abrasive disc on the surface of the composites as the wear mechanism. Process optimization and predictive modelling using response surface method of the design expert version 11.0 revealed the optimal wear process factors and properties with their levels of interactions at a reinforcement particle size of $154.710 \mu \mathrm{m}$ and volume fraction of $20.451 \%$. Numerical optimization models were also generated for predicting the wear properties at given process factors. The results of this investigation revealed that the developed wood charcoal composites is recommendable for several lightweight structural and tribological applications such as wheels, rollers, clutches, gears, seal cams and other bearing materials.

(C) 2021 Published by Faculty of Engineering 


\section{INTRODUCTION}

Sliding wear is a complex phenomenon that come into play when two or more Solid surfaces in relative motion undergo progressive loss of materials [1,2]. Wear and tribology are two terms that are most times used interchangeably in the literature. Tribology is a scientific study that deals with the design, wear, lubrication and friction performance of interacting surfaces in relative motion [3]. When under an external load, two materials are in contact with each other, the asperities of two surfaces come into close contact and during sliding motion, deterioration of the surfaces known as wear does occur. During the sliding process of softer materials against harder materials, atoms are taken off from the softer surface and these atoms tend to attach themselves in the asperities of the harder surface. A cold welding process thus occurs in the contact surface and interatomic junctions across the interface $[3,4]$. By continuing the sliding process, a fracture can take place at the junctions causing the detachment or dislodgement of particles from adhering asperities. During the sliding movement of two surfaces under an applied load, friction force causes shear at the interatomic junctions $[3,4]$. Wear of composite materials can be categorized into the following classes, depending on the mechanism by which materials are removed from the surface of interacting bodies; abrasive wear, adhesive wear, fatigue wear, erosive wear, fretting wear, oxidative wear and corrosive wear $[1,2,5,6]$. During abrasive wear, materials are removed by the dynamic interaction of two surfaces in relative contact, resulting in dimensional loss and reduction in the volume of the material [1]. During sliding and abrasive wear of particlefilled polymer composites, there is a microscopic ploughing and cutting away of contact surfaces by hard matter at the interface, known as a micro-cutting mechanism $[2,5]$. Typical examples of this wear mechanism are wear of wheels or rails by sand particles. Polymer composite materials hold more promises for several structural and tribological applications such as wheels, rollers, clutches, gears, seal cams and bearing material [7], owing to their possession of such properties as, high stiffness and strength to weight ratio, resistance to chemical attacks, ease of fabrication, self-lubrication and low friction
[5,8-11]. According to Bagherpour, the improved properties of composites over monolithic materials, show that they majorly depend on; the properties of the components in the composite; the relative amount or concentration of different phases; the orientation of various components; the degree of bonding between the matrix and the reinforcements and the size, shape and distribution of the discontinuous/reinforcing phase [12]. Composites are produced when two or more materials or phases are used together to give a combination of properties that cannot be achieved using the individual materials [12]. There is, however, an increasing research effort to employ natural fibres and particulate reinforcements for polymer composites in mechanical and tribological applications $[13,14]$. The properties of the incorporated reinforcements affect the tribological performance of polymer matrix composite materials, thus, any effort to improve their friction and wear characteristics will require using reinforcements that will improve properties such as; hardness, stiffness and compressive strength, etc. [2]. Polymer matrix composites are manufactured commercially for diverse applications in industries like; sporting goods, aerospace components, automobiles and chemical industries $[2,13,15,16]$. Several pieces of research that utilized agricultural wastes as reinforcement for polyester matrix composites have reported improvement on their mechanical and tribological properties [13,1722]. The use of natural or organic reinforcement materials in polymeric systems has become widespread. Among the reasons adduced for the widen research efforts on the application of natural fibre and particle reinforced composites are; increasing global awareness and concern for environmental protection and stiffer legislation, availability of natural fibres of plant and animal origins in large quantity, and many desirable properties of natural fibre composites [19]. Wide usage of these natural fibre/filler reinforced composites over other materials are due to the pecific properties of natural fibre composite such as light weight, low cost, renewable nature, high specific strength and modulus [21,23-26].

During the preparation of polymer matrix composites, commonly used thermoset resins are unsaturated polyesters, epoxies, vinyl esters, and 
phenolic [2,5,8,12,15,26-29]. Out of these, unsaturated polyester resin represents approximately $75 \%$ of the total resins used in the composites industries. Polyesters are considered as versatile due to their ability to be modified during the formation of polymer chains $[12,30]$. Common industrial applications of polyester composites include; bearing materials, brake pads materials and flooring materials [16]. Recently, researchers are beginning to consider charcoal powder as reinforcement for the improvement of mechanical and electrical properties of polymer matrix composites [31,3336]. Charcoal is the main product of wood charring process, known as the pyrolysis. It is not purely carbon in itself but comprises of both primary carbon and secondary deposit of tar in a complex combination [31-33]. Wood charcoal if it yield satisfactory research results, could be considered an alternative option to partly replace conventional synthetic fillers due to its availability in large quantity at relatively low cost.

Response surface methodology (RSM), has been successfully utilized among other experimental design and optimization techniques for the predictive modelling and process factor optimization of composite materials [37-39]. RSM is a statistical and experimental design tool in which a specified dependent variable or materials property responds to experimental variations in one or more independent process factors [40-43]. There is little or no researches on the use of hardwood charcoal to improve the tribological and other mechanical properties of wood charcoal-polymer composites $[38,44]$. Therefore, the objective of the present research is to investigate the influence of hardwood charcoal Particles (HWCP), as natural reinforcement material on the density and dry sliding wear resistance of polyester matrix composite, as well as optimize the process factors (reinforcement particle sizes and volume fraction) and develop mathematical models for predicting the investigated properties.

\section{EXPERIMENTAL TECHNIQUES}

\subsection{Materials}

The materials used in this study were obtained locally, and they include hardwood charcoal particles (HWCP) as reinforcement, unsaturated polyester resin as matrix, methyl-ethyl-ketone peroxide (MEKP) catalyst and cobalt naphthanate as an accelerator.

\subsection{Preparation of hardwood charcoal/polyester composites}

The development of the hardwood charcoal particles reinforced polyester matrix composites and the neat/ unreinforced polyester followed the procedure described in the authors' previous work [44].

\subsection{Characterization of properties}

\section{Measurement of experimental density}

ASTM 792 standard procedure was adopted to ascertain the experimental density of the synthesized composites. Clean samples of the composites were weighed accurately using an electrical scale and then submerged in water. The weight of the samples when submerged in water was determined, the volume of the sample was determined from the effect of displacement of water (Archimedean principle). The density was calculated using the expression given in equation (1) and the experimental density of the composite tabulated (Table 1).

$$
\text { Density }=\frac{\text { Mass }}{\text { Volume }}
$$

\section{Dry sliding wear test}

Pin-on-Disc tribological tests were carried out under dry conditions, using a pin-on-disc Tribometer following the guidelines of the ASTM G99-04 standard. The dry sliding wear test was carried out by applying a constant load of $10 \mathrm{~N}$ on all the $40 \mathrm{~mm} \times 10 \mathrm{~mm} \times 6 \mathrm{~mm}$ specimens using the following procedure; initial weighing of the specimen, inserting and fixing the specimen on the specimen holder, applying the load on the supporting rod so that the stylus pin made firm contact with the specimen, switching the electric motor on to rotate the specimen for just 2000 cycles, final weighing of the specimen, and measuring the sliding distance [13]. A constant load was chosen for the tribological test because it has been demonstrated that abrasive wear of 
particulate reinforced polymer matrix composites depended largely on the particle sizes of the filler than on the sliding load [10]. The wear evaluation was done by expressing the friction effects in terms of material volume loss $\left(\mathrm{mm}^{3}\right)$ as a function of the sliding distance according to Archad formula $[3,45]$.

$$
V_{w}=\frac{c P d}{H}
$$

where $c, P, d$ and $H$ are wear coefficient, applied load, sliding distance, and hardness of the substrate/softest contacting surfaces, respectively.

Wear volume loss can also be determined using equation $(3)[6,45]$ given below:

$$
V_{\text {loss }}=\frac{\text { Weight } \operatorname{Loss}(\mathrm{g})}{\text { Density }\left(\mathrm{g} / \mathrm{mm}^{3}\right)} \times 1000
$$

Wear rate for each sample was also estimated by dividing the value obtained from the volume loss by the sliding distance according to equation (4), the inverse of which gave the wear resistance according to equation (5) $[18,45]$. Equation (6) [11] can be used to specify wear rate, $\mathrm{W}_{\mathrm{S}}$, an important tribological property, known as the specific.

Wear rate $\left(\mathrm{mm}^{3} / \mathrm{Nm}\right)=\frac{\text { Volume loss }\left(\mathrm{mm}^{3}\right)}{\text { Sliding Distance }(\mathrm{m})} \times 1000$

Wear Resistance $\left(\mathrm{mm} / \mathrm{mm}^{3}\right)=\frac{\text { Sliding Distance }}{\text { Volume loss }} \times 1000$

$W_{S}=\frac{\text { Weight Loss }}{\text { Density } \times \text { Applied Load } \times \text { Sliding Distance }}=$

$\frac{\text { Volume Loss }}{\text { Applied Load } \times \text { Sliding Distance }}$

The computed sliding wear results and all the wear parameters are given in Table 4.

\section{Scanning electron microscopy study of wear surface}

The worn surfaces of the tribological samples were scanned and examined by SEM-EDX technique at an accelerating voltage of $15 \mathrm{kV}$ and various magnifications (500, 1000 \& 1500x) using a Phenom Pro X Model SEM (Phenomworld, Eindhoven, Netherlands) equipped with Energy Dispersive X-ray spectroscopy (EDX). The generated SEM morphology is electronically transmitted to
EDX coupled with elemental identification software that automatically characterized the major, minor and trace elemental constituents of the samples in both atomic and weight percentages.

\subsection{Response surface modelling and optimization of wear parameters}

Central composite design type of the response surface methodology (RSM) experimental design of the Design-Expert Software version 11 was employed to statistically analyse, model and optimize the experimental results. During the analysis, a quadratic design model was applied. The reinforcement content (wt.\%) and particle sizes $(\mu \mathrm{m})$ were set as the independent variables (Factors X \& Y), while Volume Loss $\left(\mathrm{mm}^{3}\right)$, specific wear rate $\left(\mathrm{mm}^{3} / \mathrm{Nm}\right)$, wear resistance $\left(\mathrm{mm} / \mathrm{mm}^{3}\right)$ and experimental density $\left(\mathrm{g} / \mathrm{cm}^{3}\right)$ were set as the response variables (Responses 1 to 4) [38]. Twenty-eight runs of experiments were performed to obtain the responses of the dependent variables/composite properties. Statistical significance of the experimental results was evaluated using analysis of variance (ANOVA). Predictive model equations were derived for volume loss, specific wear rate, wearresistance and density as a function of the filler content and particle sizes in terms of coded factors. Numerical optimization solutions reported the optimal level of the composite parameters/factors that will result in minimum wear rate and optimal combination of other composite properties.

\section{RESULTS AND DISCUSSION}

\subsection{Experimental density of HWCP/Polyester matrix composites}

Table 1 gives the parameters for the determination of experimental density and the experimental density of the HWCP reinforced polyester matrix composites. While Figures 1 and 2 are used to analyse the influence of the reinforcement percentage weight fractions and particle size respectively on the experimental density of the produced composites.

The experimental densities of the HWCP/polyester composites decrease with 
increasing weight fractions of the hardwood charcoal particles addition and particle size of the reinforcement (Figure $1 \& 2$ ). This as expected, will lead to the production of lightweight polymer matrix composites but may also give rise to pores in the composites internal structures. The reduction in densities was remarkable for larger reinforcement particles (250 \& $300 \mu \mathrm{m})$ as larger volume spaces are occupied in the polyester matrix structure by the larger hardwood charcoal particles, due to large surface area.

Table 1. Experimental densities of the HWCP reinforced polyester matrix composites and the unreinforced polyester.

\begin{tabular}{|c|c|c|c|c|}
\hline $\begin{array}{c}\text { Reinforcement } \\
\text { Particle Size }(\mu \mathrm{m})\end{array}$ & $\begin{array}{l}\text { Percentage Weight of } \\
\text { Reinforcement (wt\%) }\end{array}$ & $\begin{array}{c}\text { Mass of } \\
\text { Composite (g) }\end{array}$ & $\begin{array}{l}\text { Volume of } \\
\text { composite } \\
\left(\mathrm{cm}^{3}\right)\end{array}$ & $\begin{array}{c}\text { Experimental Density } \\
\text { of composite }(\rho \mathrm{EX}) \\
\left(\mathrm{g} / \mathrm{cm}^{3}\right)\end{array}$ \\
\hline \multirow{7}{*}{75} & 0.0 & 0.94 & 0.9 & 1.044 \\
\hline & 5.0 & 0.89 & 0.85 & 1.047 \\
\hline & 10.0 & 1.22 & 1.2 & 1.017 \\
\hline & 15.0 & 1.04 & 0.85 & 1.224 \\
\hline & 20.0 & 1.08 & 1 & 1.080 \\
\hline & 25.0 & 0.95 & 0.75 & 1.267 \\
\hline & 30.0 & 1 & 0.96 & 1.042 \\
\hline \multirow{6}{*}{150} & 5.0 & 1.01 & 0.98 & 1.031 \\
\hline & 10.0 & 0.89 & 0.8 & 1.113 \\
\hline & 15.0 & 1.03 & 0.79 & 1.304 \\
\hline & 20.0 & 0.8 & 0.9 & 0.889 \\
\hline & 25.0 & 0.84 & 0.8 & 1.050 \\
\hline & 30.0 & 0.96 & 0.99 & 0.970 \\
\hline \multirow{6}{*}{250} & 5.0 & 0.85 & 0.65 & 1.308 \\
\hline & 10.0 & 1.04 & 0.7 & 1.486 \\
\hline & 15.0 & 0.87 & 0.82 & 1.061 \\
\hline & 20.0 & 1.08 & 1.09 & 0.991 \\
\hline & 25.0 & 0.87 & 0.9 & 0.967 \\
\hline & 30.0 & 0.7 & 0.8 & 0.875 \\
\hline \multirow{6}{*}{300} & 5.0 & 0.94 & 0.9 & 1.044 \\
\hline & 10.0 & 1.1 & 1.02 & 1.078 \\
\hline & 15.0 & 0.92 & 1 & 0.920 \\
\hline & 20.0 & 0.99 & 1 & 0.990 \\
\hline & 25.0 & 0.96 & 0.9 & 1.067 \\
\hline & 30.0 & 0.77 & 0.94 & 0.819 \\
\hline
\end{tabular}

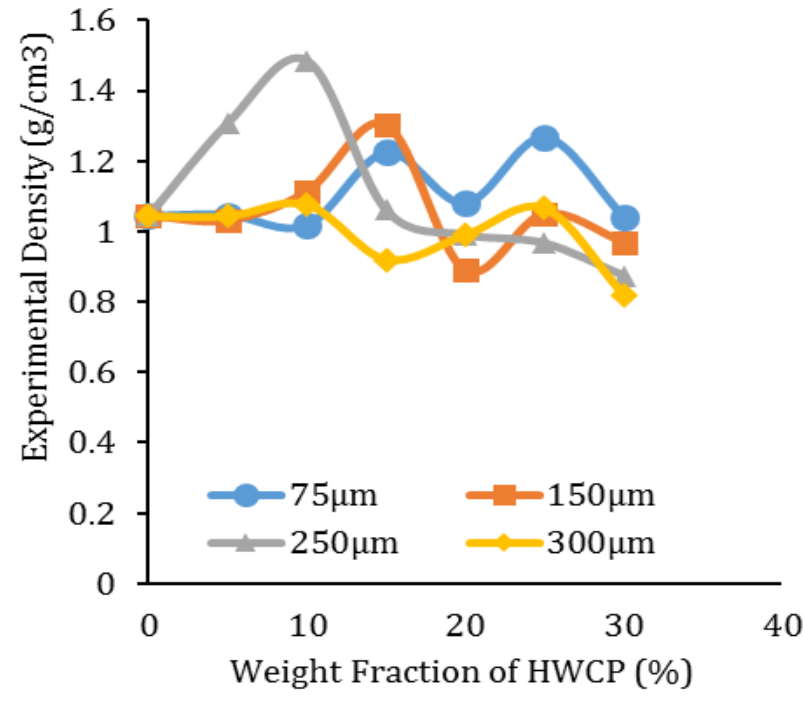

Fig 1. Effect of reinforcement weight fraction on the experimental density of HWCP/Polyester matrix composites.

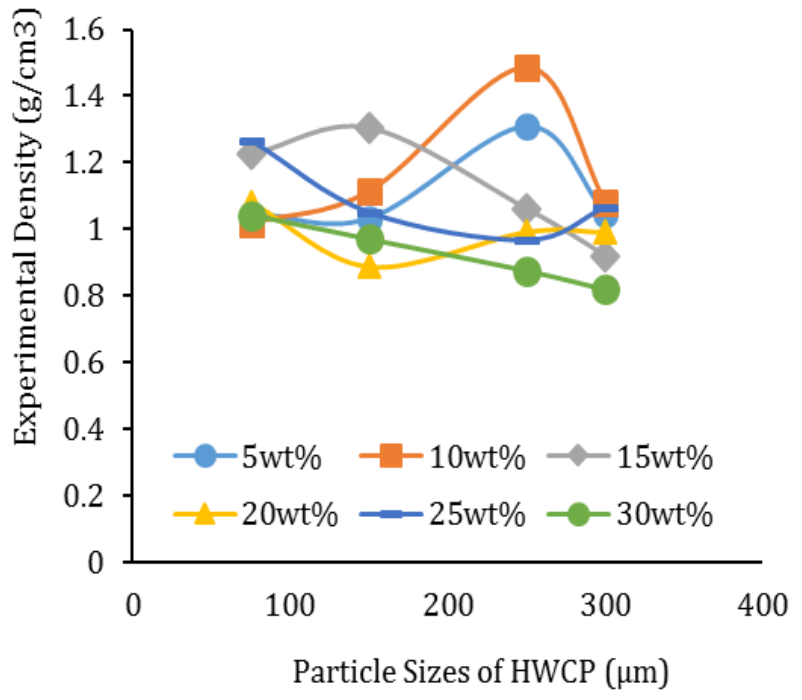

Fig 2. The effects of reinforcement particle size on the experimental density of HWCP/Polyester matrix composite. 


\subsection{Dry sliding wear behaviour of HWCP/Polyester matrix composites}

The influences of reinforcement particle sizes, reinforcement content, applied normal load and sliding speed on the dry sliding wear properties (weight loss, volume loss, specific wear rate and wear resistance) are determined in this investigation. Table 2 provides the result of the wear test and the sliding wear parameters. Graphical analysis of the influence of the reinforcement content $(\%$ weight fraction) and particulate sizes $(\mu \mathrm{m})$ on the specific wear rate, volume loss and wear resistance of the HWCP reinforced polyester matrix composites are given in Figures 3, 4, 5, 6 , and 7 respectively. It could be readily observed from Table 2 that the weight loss of the composites increased as the reinforcement content increases for all the particle sizes. It is expected that the wear rate will also increase. As observed from Table 2, the developed composites exhibited slightly good wear properties at lower reinforcement content and larger particle sizes. During the sliding motion of the hard abrasive disc on the sample, the total area or amount of materials that are cut/ploughed away from the surface of the composite by one Newton load/force could be measured as the specific wear rate $\left(\mathrm{mm}^{3} / \mathrm{Nm}\right)$.

Table 2. Dry sliding wear parameters and results of dry sliding wear test.

\begin{tabular}{|c|c|c|c|c|c|}
\hline Sample & Weight loss (g) & Sliding Distance (mm) & $\begin{array}{c}\text { Volume Loss } \\
\left(\mathrm{mm}^{3}\right)\end{array}$ & $\begin{array}{c}\text { Specific Wear Rate } \\
\left(\mathrm{mm}^{3} / \mathrm{Nm}\right)\end{array}$ & $\begin{array}{c}\text { Wear Resistance } \\
\left(\mathrm{mm} / \mathrm{mm}^{3}\right)\end{array}$ \\
\hline Control & 0.0006 & 1.2 & 0.575 & 0.048 & 2086.96 \\
\hline A1 & 0.0005 & 2.2 & 0.478 & 0.022 & 4602.51 \\
\hline $\mathrm{A} 2$ & 0.0081 & 2.1 & 7.965 & 0.379 & 263.65 \\
\hline A3 & 0.0146 & 1.9 & 11.928 & 0.628 & 159.29 \\
\hline $\mathrm{A} 4$ & 0.0007 & 4.3 & 0.648 & 0.015 & 6635.80 \\
\hline A5 & 0.0056 & 3.6 & 4.420 & 0.123 & 814.48 \\
\hline A6 & 0.0066 & 0.9 & 6.334 & 0.704 & 142.09 \\
\hline B1 & 0.0002 & 4.9 & 0.194 & 0.004 & 25257.73 \\
\hline $\mathrm{B} 2$ & 0.0011 & 4.5 & 0.988 & 0.022 & 4554.66 \\
\hline B3 & 0.0019 & 1.2 & 1.457 & 0.121 & 823.61 \\
\hline B4 & 0.0044 & 4.9 & 4.949 & 0.101 & 990.10 \\
\hline B5 & 0.0008 & 1.4 & 0.762 & 0.054 & 1837.27 \\
\hline B6 & 0.0020 & 4.8 & 2.062 & 0.043 & 2327.84 \\
\hline $\mathrm{C} 1$ & 0.0015 & 2.5 & 2.308 & 0.092 & 1083.19 \\
\hline $\mathrm{C} 2$ & 0.0069 & 2.9 & 9.857 & 0.340 & 294.21 \\
\hline C3 & 0.0061 & 1.65 & 7.439 & 0.451 & 221.80 \\
\hline C4 & 0.0053 & 0.9 & 4.862 & 0.540 & 185.11 \\
\hline $\mathrm{C} 5$ & 0.0016 & 0.9 & 1.778 & 0.198 & 506.19 \\
\hline C6 & 0.0014 & 1.9 & 1.750 & 0.092 & 514.29 \\
\hline D1 & 0.0005 & 3.56 & 0.556 & 0.016 & 6402.88 \\
\hline D2 & 0.0024 & 4.15 & 2.353 & 0.057 & 1763.71 \\
\hline D3 & 0.0012 & 2.1 & 1.200 & 0.057 & 1750 \\
\hline D4 & 0.0004 & 2.0 & 0.400 & 0.020 & 5000 \\
\hline D5 & 0.0012 & 2.0 & 1.333 & 0.067 & 1500.38 \\
\hline D6 & 0.0037 & 2.6 & 3.936 & 0.151 & 660.57 \\
\hline
\end{tabular}

Figure 3 depicts the variation of specific wear rate of the HWCP reinforced polyester matrix composite with the particle sizes of the hardwood charcoal. While Figure 4 is used to analyse the impact of the reinforcement concentration on the specific wear rate of the developed composites. An initial significant decrease in the wear rate was observed for all reinforcement concentration as the reinforcement particle sizes increased from 75 to $150 \mu \mathrm{m}$, followed by an increase between 150 to $250 \mu \mathrm{m}$, and a final decrease between 250 and $300 \mu \mathrm{m}$. This trend is except for $20 \mathrm{wt} \%$ samples, which increased up to $250 \mu \mathrm{m}$ before decreasing at $300 \mu \mathrm{m}$ (Figure 5). From Figure 6, all the specimens (A - D) have lower specific wear rate than the neat polyester at 5 wt $\%$ reinforcement content, except the $250 \mu \mathrm{m}$ (specimen C) which recorded a wear rate slightly higher than that of the unreinforced sample. The lowest specific wear rate of $0.004 \mathrm{~mm}^{3} / \mathrm{Nm}$ was 
obtained by the $150 \mu \mathrm{m}$ particle size at $5 \mathrm{wt} \%$ reinforcement concentration. It could be observed from Figure 4 also, that the wear rate for the $300 \mu \mathrm{m}$ samples was lower than the unreinforced polyester at all reinforcement concentrations except the $30 \mathrm{wt} \%$. This show that the higher the particle size of the hardwood charcoal, the better the abrasive wear properties of the hardwood charcoal/polyester matrix composites [10]. The higher wear rate observed in low filler composites could be attributed to weak interfacial interactions between the matrix and the reinforcements particles [46]. The maximum specific wear rate of $0.704 \mathrm{~mm}^{2} / \mathrm{N}$ was recorded by the $75 \mu \mathrm{m}$ sized hardwood charcoal particle at $30 \mathrm{wt} \%$ reinforcement content. Increased wear volume loss as observed in Figure 5 from above $5 \mathrm{wt} \%$ reinforcement content could be as a result of catastrophic ploughing and dislodging of the exposed reinforcement particles from the uppermost surface of the composites as soon as they come in contact with the progressively sliding wear disc [46]. At above 15 $\mathrm{wt} \%$ of the reinforcement, there was a significant reduction in the volume loss as more particulate reinforcement forms an abrasive layer which may have increased the coefficient of friction, hence the decreased wear volume loss that followed [13,14]. This formation of reinforcement surface film/abrasive layer on the counterface has been confirmed as the mechanism responsible for improving wear characteristics of particulate reinforced polymer matrix composites [2].

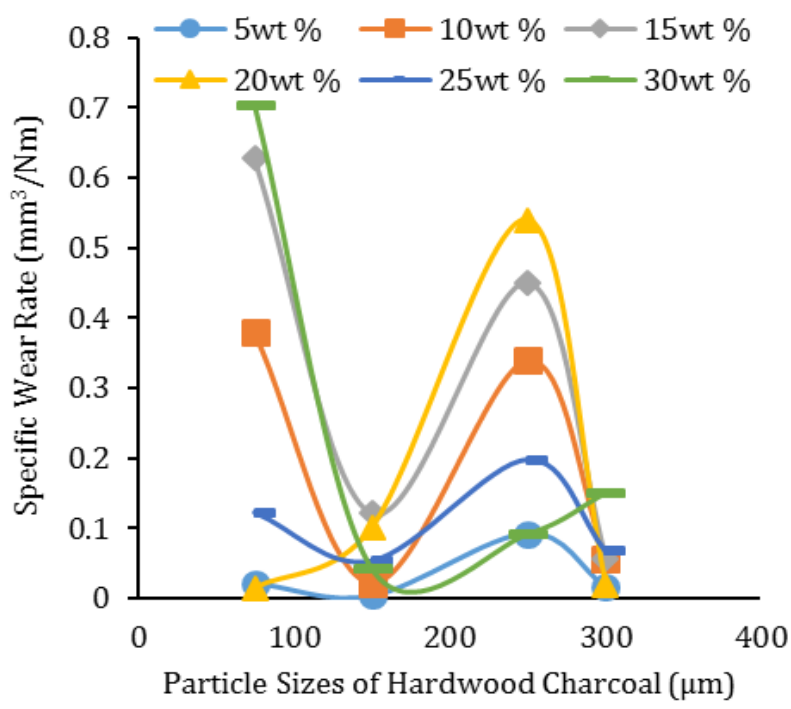

Fig 3. Variation of reinforcement particle sizes with the specific wear rate of HWCP/Polyester matrix composites.

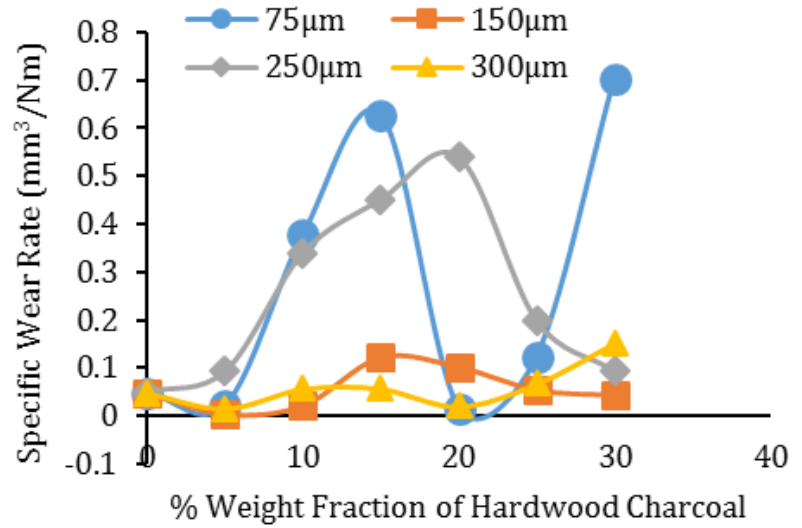

Fig 4. Influence of the reinforcement weight fraction (\%) on the specific wear rate of HWCP/Polyester matrix composites.

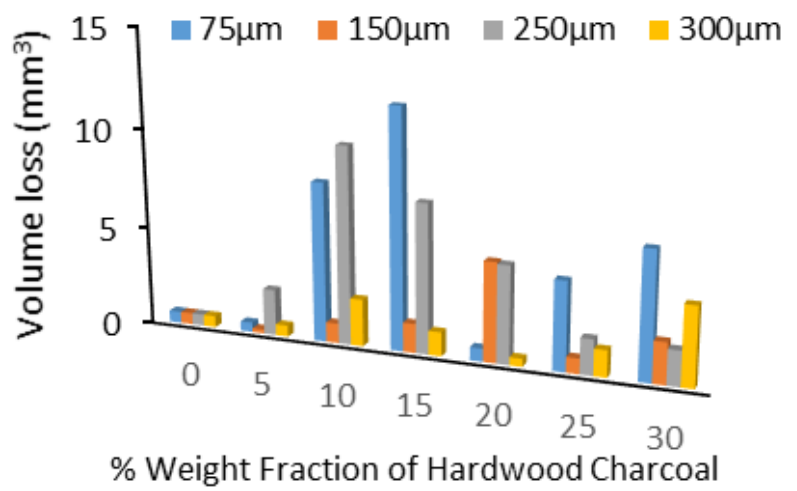

Fig 5. Effect of reinforcement \% weight fraction on the volume loss of HWCP/Polyester matrix composites during dry sliding wear.

Figure 6 is used to examine the influence of the hardwood charcoal concentration on the resistance offered to slide wear per unit area of the HWCP/polyester composite sample. It is clear from the graph that the $150 \mu \mathrm{m}$-sized reinforcement exhibited the greatest resistance to abrasive wear at $5 \mathrm{wt} \%$ reinforcement loading. This also informed why this composite sample recorded the lowest weight loss, volume loss and specific wear rate obtained in this investigation. Figure 7 on the other hand, brings out the impact of each particle sizes of the reinforcement used on the wear resistance of the produced particulate reinforced polyester composites. It could be seen in Figure 7, that the wear resistance increased for all the reinforcement concentration as the reinforcement particle size was increased from 250 to $300 \mu \mathrm{m}$. This show that large particle sizes of reinforcement are the likely choice for the improvement of wear resistance than small ones, as they sufficiently resist the shearing force of the abrasive disc sliding on the wear specimen and prevent the ease of dislodgement of the 
reinforcement particles [10]. Figure 7 also revealed that the resistance offered to slide wear was higher for all the composites at $5 \mathrm{wt} \%$ than the unreinforced polyester, except for the $250 \mu \mathrm{m}$ composite samples which exhibited a reduction in wear resistance at all the studied reinforcement concentrations.

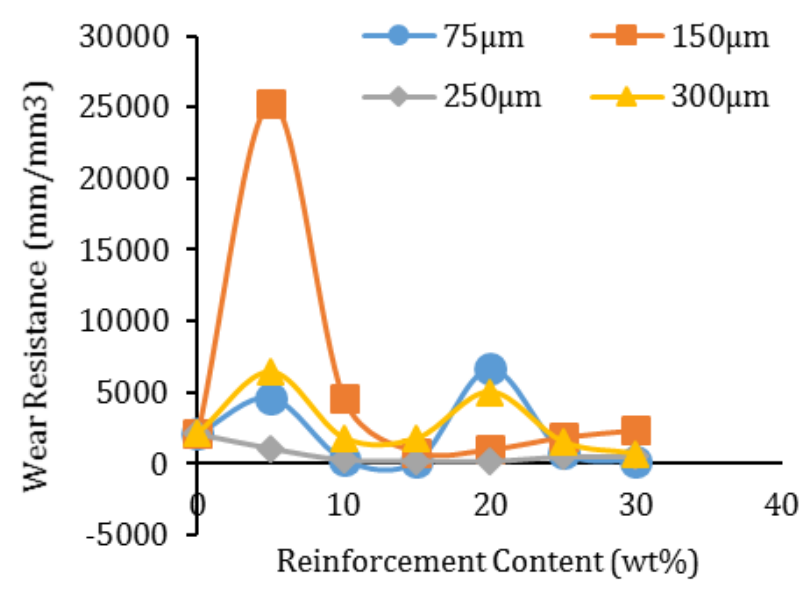

Fig 6. Influence of reinforcement concentration on the wear resistance of $\mathrm{HWCP} /$ polyester matrix composites.

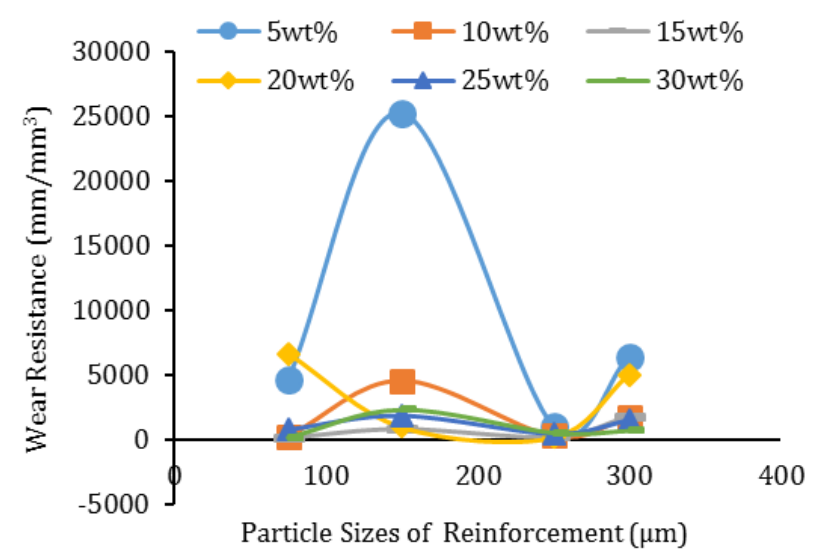

Fig 7. Variation of reinforcement particle sizes with the wear resistance of the HWCP/polyester matrix composites.

\subsection{Morphological and EDX characterization of worn surface of HWCP/Polyester matrix composites}

Figures 8 and 9 show the SEM morphology of unreinforced polyester and $300 \mu \mathrm{m} / 15 \mathrm{wt} \% \mathrm{HWCP}$ reinforced polyester composite with their corresponding elemental compositions characterized and quantified by EDX. EDX data for the HWCP reinforced polyester composites revealed an increase in the concentration of carbon from $69.26 \mathrm{wt} \%$ in the unreinforced polyester to $80.42 \mathrm{wt} \%$. The previous result on the XRD characterization of wood charcoal powder also revealed sharp peaks of carbon in the form of graphite forming large turbostatic crystallites [32].

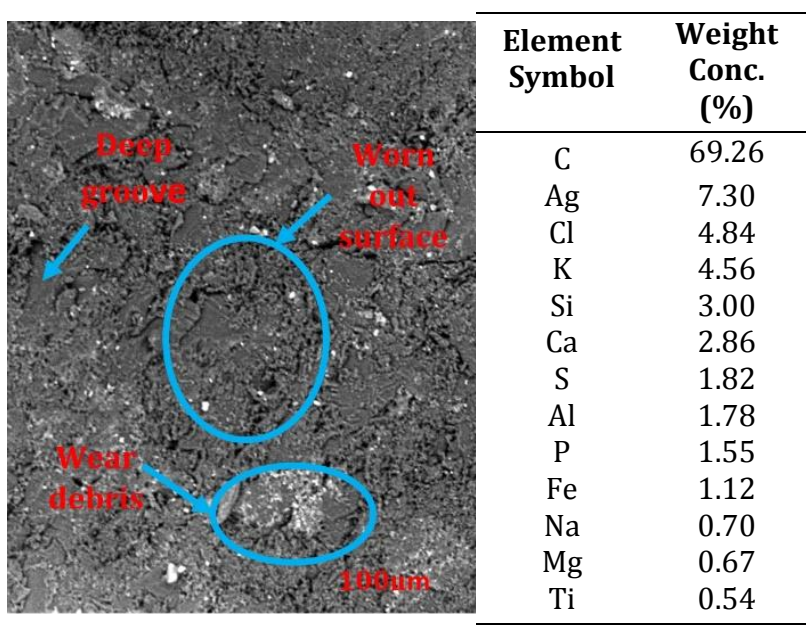

Fig 8. SEM micrograph of the worn surface and corresponding EDX elemental mapping of unreinforced polyester.

\begin{tabular}{|c|c|c|}
\hline 2 & $\begin{array}{c}\text { Element } \\
\text { Symbol }\end{array}$ & $\begin{array}{c}\text { Weight } \\
\text { Conc. } \\
\text { (\%) }\end{array}$ \\
\hline & $\mathrm{C}$ & 80.42 \\
\hline & $\mathrm{Ag}$ & 4.32 \\
\hline & $\mathrm{Si}$ & 2.30 \\
\hline & $\mathrm{K}$ & 2.04 \\
\hline & $\mathrm{Cl}$ & 1.97 \\
\hline$\infty$ & $S$ & 1.67 \\
\hline & $\mathrm{Fe}$ & 1.63 \\
\hline & $\mathrm{Ca}$ & 1.59 \\
\hline 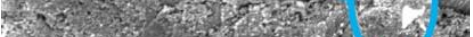 & $\mathrm{Al}$ & 1.42 \\
\hline & $\mathrm{P}$ & 1.33 \\
\hline & $\mathrm{Mg}$ & 0.84 \\
\hline (67) 10040 & $\mathrm{Na}$ & 0.47 \\
\hline
\end{tabular}

Fig 9. SEM micrograph and corresponding EDX elemental mapping for $300 \mu \mathrm{m}$ and $15 \mathrm{wt} \% \mathrm{HWCP}$ reinforced polyester matrix composite.

The interfacial morphologies shown by SEM images of Figures 10 to 14 revealed that the wear mechanism was mainly by abrasive dislodgement of a chunk of composite particles. A formation of smooth, deep and discontinuous furrows caused by ploughing and micro-cutting of particles from the composites during the sliding motion can be observed on the micrographs, especially the worn surface of $150 \mu \mathrm{m}$ and $15 \mathrm{wt} \%$ particulate charcoal reinforced polyester matrix composite (Figure 11). Earlier morphological investigations had also identified micro-ploughing/cutting mechanism caused by progressive surface damage as typical of particle reinforced polymer matrix composites [2]. 


\subsection{Statistical analysis, modelling and optimization of HWCP/Polyester matrix composites' properties}

The results from statistical analysis, modelling and optimization show that the Volume Loss $\left(\mathrm{mm}^{3}\right)$, specific wear rate $\left(\mathrm{mm}^{3} / \mathrm{Nm}\right)$, wear resistance $\left(\mathrm{mm} / \mathrm{mm}^{3}\right)$ and experimental density $\left(\mathrm{g} / \mathrm{cm}^{3}\right)$ are functions of the independent variables; reinforcement volume fraction (wt\%) and particle sizes $(\mu \mathrm{m})$. The summary of the design settings and build information for the factors and responses are contained in Tables $3 \mathrm{a}$ $\&$ b. The design builds information present details of the analysis and design model type among other things.
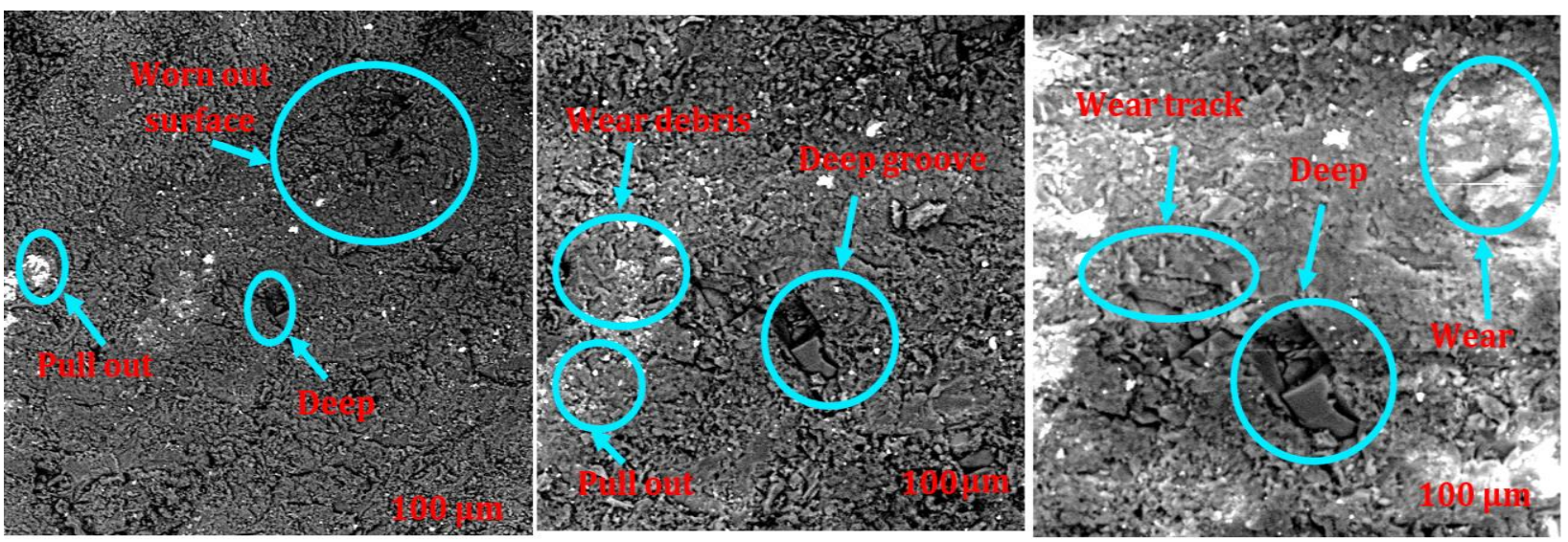

Fig 10. SEM micrograph of worn surface for $75 \mu \mathrm{m}$ and $15 \mathrm{wt} \%$ particulate charcoal reinforced polyester matrix composite scanned at 500, 1000 \& 1500 magnifications.
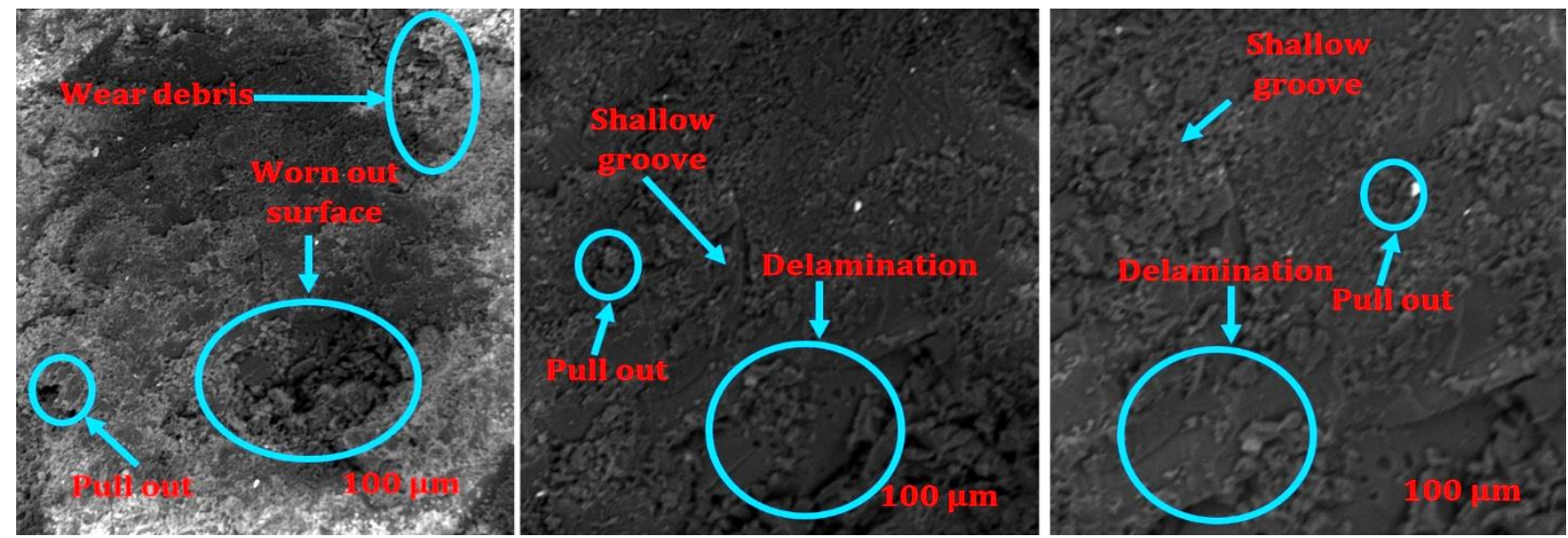

Fig 11. SEM micrograph of worn surface for $150 \mu \mathrm{m}$ and $15 \mathrm{wt} \%$ particulate charcoal reinforced polyester matrix composite scanned at 500, 1000 \& 1500 magnifications.
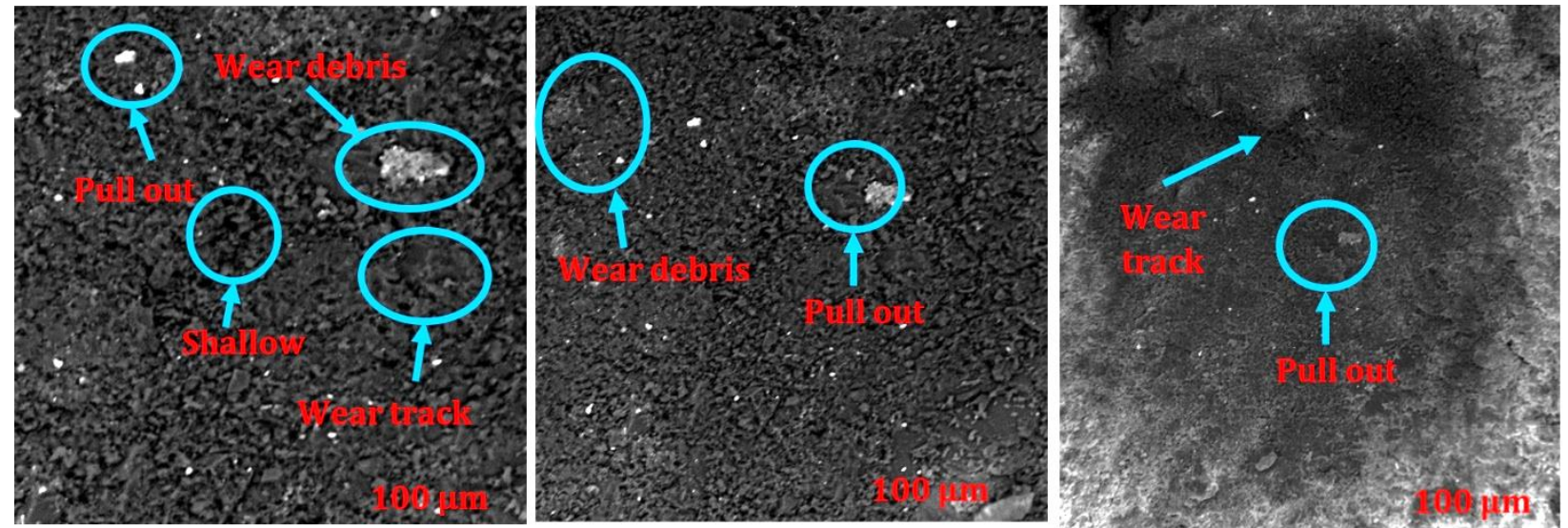

Fig 12. SEM micrograph of worn surface for $250 \mu \mathrm{m}$ and $15 \mathrm{wt} \%$ particulate charcoal reinforced polyester matrix composite scanned at various magnifications. 

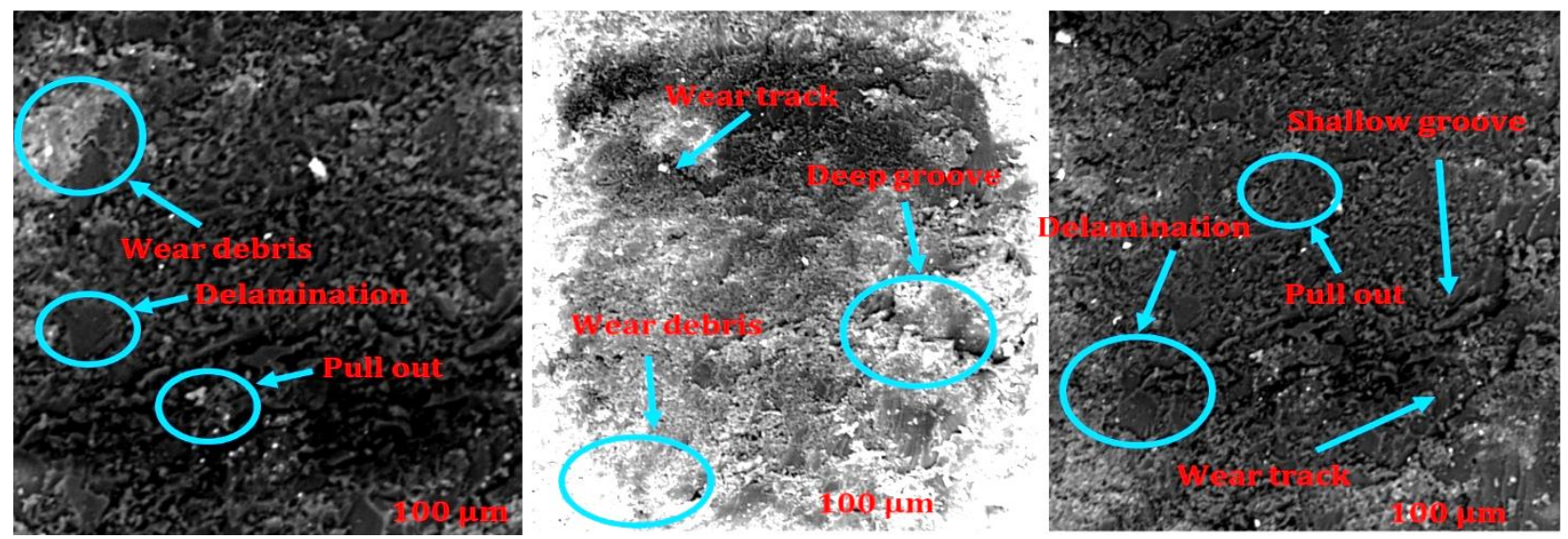

Fig 13. SEM micrograph of worn surface for $300 \mu \mathrm{m}$ and $15 \mathrm{wt} \%$ particulate charcoal reinforced polyester matrix composite scanned at 1500 magnification.
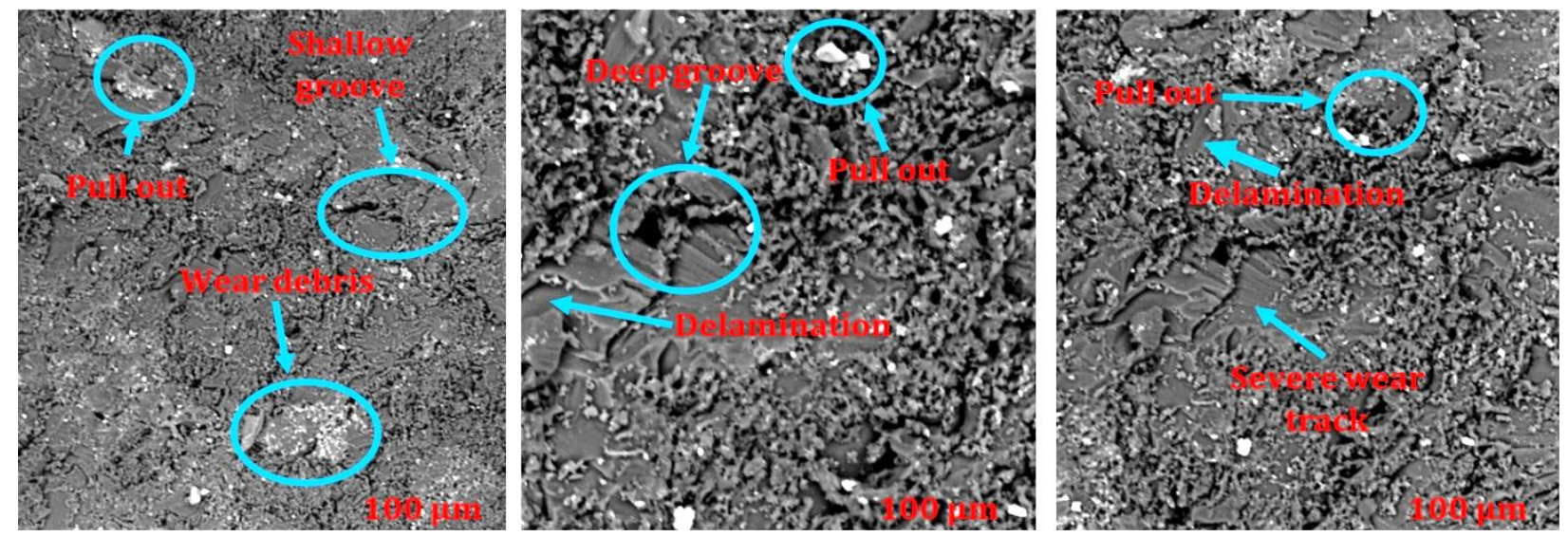

Fig 14. SEM micrograph of worn surface for the unreinforced polyester resin scanned at three different magnifications.

Table 3a. Build information for the design factors.

\begin{tabular}{cccccccccc}
\hline Factor & Name & Units & Type & Min & Max & Coded Low & Coded High & Mean & Std. Dev. \\
\hline $\mathbf{X}$ & Particle Sizes & microns & Numeric & 75.00 & 300.00 & $-1 \leftrightarrow 75.00$ & $+1 \leftrightarrow 300.00$ & 193.75 & 88.88 \\
$\mathbf{Y}$ & Weight concentration & wt $\%$ & Numeric & 0.000 & 30.00 & $-1 \leftrightarrow 0.00$ & $+1 \leftrightarrow 30.00$ & 15.00 & 10.18 \\
\hline
\end{tabular}

Table 3b: Build information and design summary for the response variables.

\begin{tabular}{|c|c|c|c|c|c|c|c|c|c|c|c|}
\hline Response & Name & Units & Obs & Analysis & Min & Max & Mean & $\begin{array}{l}\text { Std. } \\
\text { Dev. }\end{array}$ & Ratio & Transform & Model \\
\hline R1 & $\begin{array}{l}\text { Volume } \\
\text { Loss }\end{array}$ & $\mathrm{mm}^{3}$ & 28 & Polynomial & 0.194 & 11.928 & 2.94 & 3.17 & 61.48 & None & Cubic \\
\hline R2 & $\begin{array}{l}\text { Specific } \\
\text { Wear Rate }\end{array}$ & $\mathrm{mm}^{3} / \mathrm{Nm}$ & 28 & Polynomial & 0.004 & 0.704 & 0.1603 & 0.1991 & 176.00 & None & Cubic \\
\hline R3 & $\begin{array}{l}\text { Wear } \\
\text { Resistance }\end{array}$ & $\mathrm{mm} / \mathrm{mm}^{3}$ & 28 & Polynomial & 142.09 & 25257.7 & 2737.11 & 4790.11 & 177.76 & None & Linear \\
\hline R4 & Density & $\mathrm{g} / \mathrm{cm}^{3}$ & 28 & Polynomial & 0.819 & 1.486 & 1.06 & 0.1424 & 1.81 & None & Quadratic \\
\hline
\end{tabular}

\section{Predictive modelling and optimization solutions}

Predictive regression equations of Volume Loss, specific wear rate, wear-resistance and experimental density respectively as Equations 7 to 10 expresses functions of the considered independent factors in terms of coded factors.
The predictive models show the relationship between the respective composite properties and the composite parametric factors. For instance, from the model equations, it could be observed that the wear resistance is linearly proportional to the parametric factors $\mathrm{x} \& \mathrm{y}$, while the specific wear rate and volume loss have a cubic relationship with the 
reinforcement weight fraction and particle size. Conversely, the experimental density exhibited a quadratic relationship with the factors. When the model equation is expressed in terms of coded factors, it can be used to make predictions about the response for given levels of each factor. By default, the high levels of the process parameters/factors considered are coded as +1 , showing maximum positive impacts of the factors on the response variables while the low levels of the factors are coded as -1 , indicating maximum negative impacts of the factors on the considered response variables $[38,41]$. The coded equation is utilized for identifying the relative impact of the factors by comparing the factor coefficients.

Volume loss $=3.91627+3.60759 x-2.26041 y-$ $0.652955 x y+0.376429 x^{2}-2.79592 y^{2}+$ $1.14912 x^{2} y+1.02643 x y^{2}-5.63486 x^{3}+$ $3.24919 y^{3}$

Specific wear rate $=0.182903+0.338317 x-$ $0.0708914 y-0.0598549 x y+0.024618 x^{2}-$ $0.0916549 y^{2}+0.103025 x^{2} y-0.0569967 x y^{2}-$ $0.420342 x^{3}+0.11475 y^{3}$

Wear resistance $=2769.11-575.986 x-$ $1970.1 y$

Experimental density $=1.14053-$ $0.0348264 x-0.0572676 y-0.0838978 x y-$ $0.032194 x^{2}-0.122089 y^{2}$

Where $\mathrm{X} \& \mathrm{Y}$ are the reinforcement particle size $(\mu \mathrm{m})$ and weight fractions (wt\%) respectively.

\section{Numerical and graphical optimization solution}

Six optimized solutions were obtained for the composite factors and the properties respectively. (Table 4). During numerical optimization, target criteria constraints/goals were specified for both the factors and the responses the criteria to find the optimal factors and responses. The composite factors (reinforcement particle size and weight fraction) were set to be in range. On the other hand, the response of wear resistance was set at maximum, while that of specific wear rate, volume loss and experimental density was set to minimum. Though the ultimate goal of numerical optimization is not to maximize the desirability value, the factor settings that result in the highest desirability value indicate there is an acceptable outcome of the numerical optimization. It is quite possible for there to be multiple islands of acceptable outcomes (local optima) to explore. A careful look through all the given solutions shows that solution five best meet the criteria applied to find the optimal settings. From the table, the solution showed that considering the independent and the dependent variables, at a reinforcement particle size of $154.710 \mu \mathrm{m}$ and volume fraction of $20.451 \%$, optimal responses of the developed HWCP reinforced polyester composite properties would be obtained.

The 3D interactive Surface plots of the wear properties with the process factors are provided in Figures 15, 16, 17, and 18 respectively. The $3 \mathrm{D}$ plots can be viewed as projection of the contour plot which give shape in addition to the colour and contour. The 3D surface plot can be rotated up and down, and left and right by dragging the plot with the mouse. Any point on the 3D surface plot can be selected to show details about the response prediction at that levels of the factors. The relative interaction of the factors (reinforcement particle sizes and volume fraction) and their magnitude of influence on the properties of the developed composites could be observed by the nature of 3D surface plots [41]. The peak level and design points above the predicted values for each property analyzed lies in the red colour.

Table 4. Optimization solutions and predicted results of the of the composite factors and wear properties.

\begin{tabular}{|c|c|c|c|c|c|c|c|c|}
\hline Number & $\begin{array}{l}\text { Particle } \\
\text { Sizes }\end{array}$ & $\begin{array}{c}\text { Weight } \\
\text { concentration }\end{array}$ & $\begin{array}{l}\text { Volume } \\
\text { Loss }\end{array}$ & $\begin{array}{c}\text { Specific } \\
\text { Wear Rate }\end{array}$ & $\begin{array}{c}\text { Wear } \\
\text { Resistance }\end{array}$ & Density & Desirability & \\
\hline 1 & 300.000 & 0.000 & -0.989 & -0.110 & 4163.226 & 1.093 & 0.518 & \\
\hline 2 & 173.325 & 0.000 & -0.536 & 0.004 & 4811.775 & 1.069 & 0.504 & \\
\hline 3 & 170.624 & 0.000 & -0.660 & -0.004 & 4825.592 & 1.068 & 0.503 & \\
\hline 4 & 137.434 & 0.000 & -1.878 & -0.083 & 4995.544 & 1.047 & 0.498 & \\
\hline 5 & 154.710 & 20.451 & 2.067 & 0.076 & 2220.996 & 1.120 & 0.442 & Selected \\
\hline 6 & 153.821 & 20.351 & 2.074 & 0.075 & 2238.687 & 1.121 & 0.442 & \\
\hline
\end{tabular}



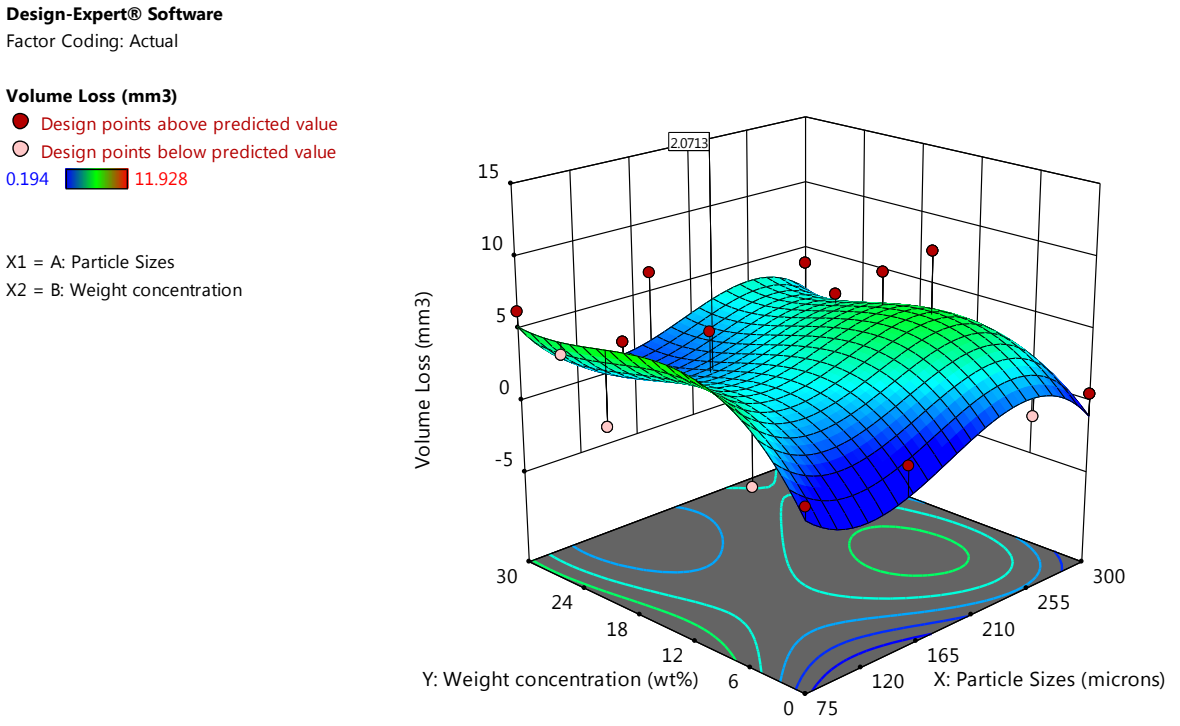

Fig 15. 3D surface plots showing the predicted responses from the numerical optimization solution for volume loss.
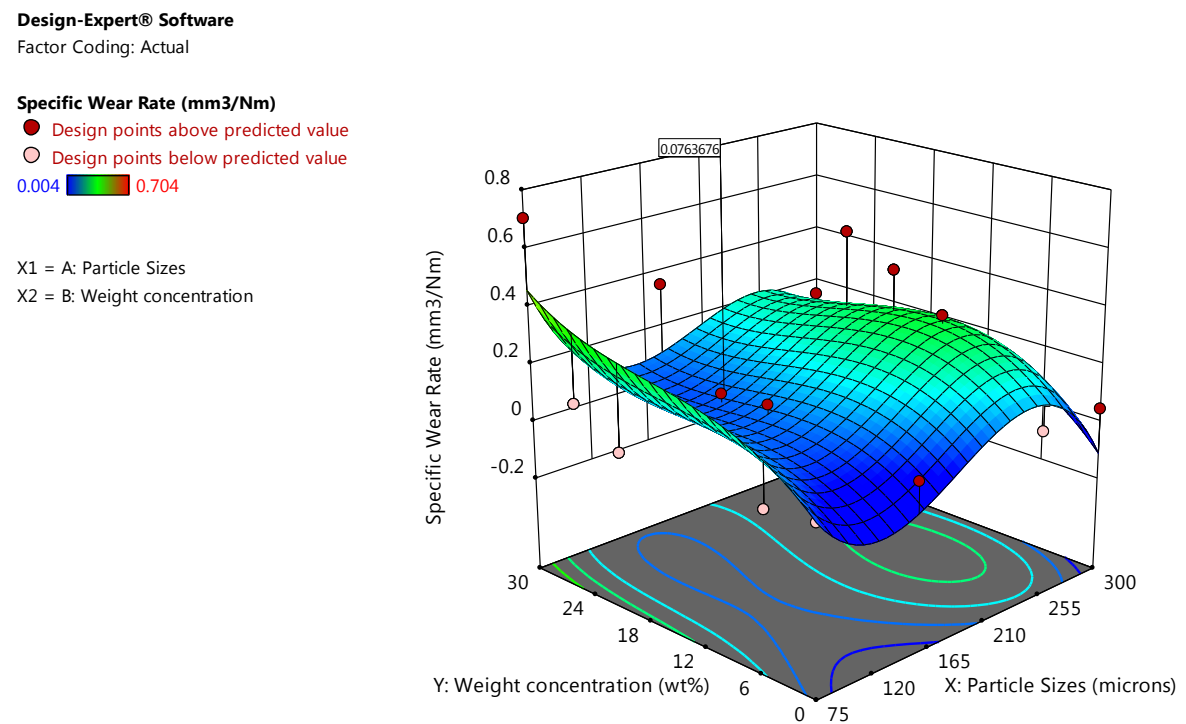

Fig 16. 3D surface plots showing the predicted responses from the numerical optimization solution for specific wear rate.
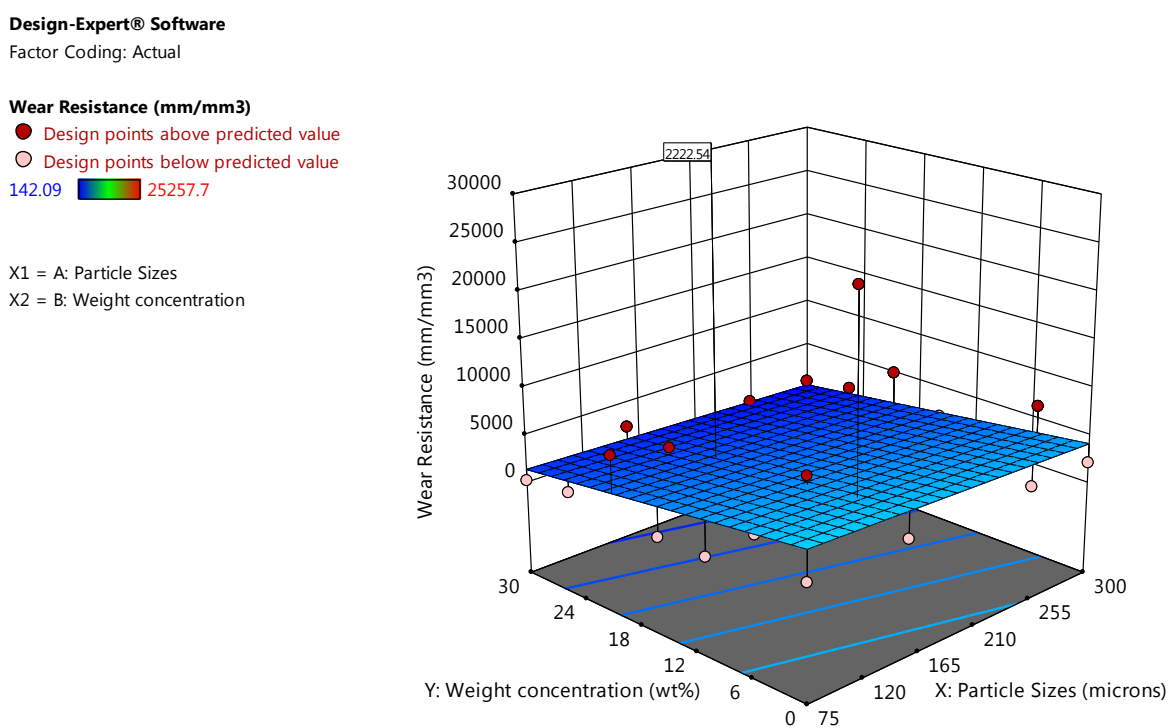

Fig 17. 3D surface plots showing the predicted responses from the numerical optimization solution for wear resistance. 

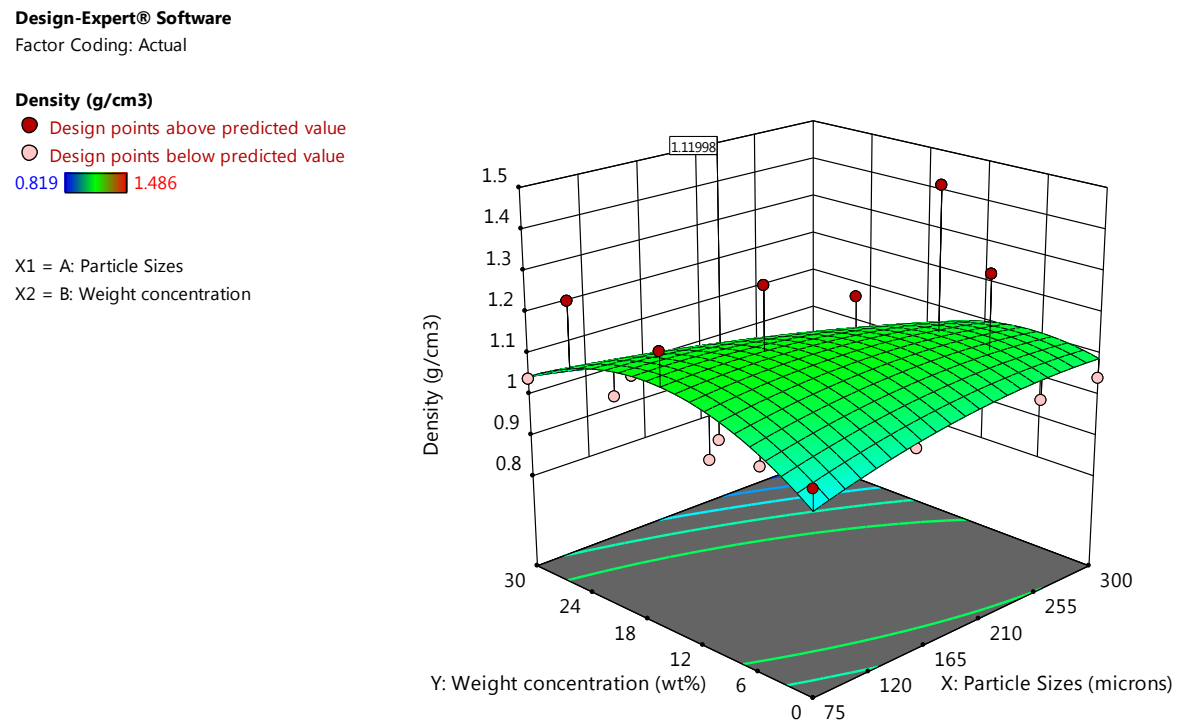

Fig 18. 3D surface plots showing the predicted responses from the numerical optimization solution for experimental density.

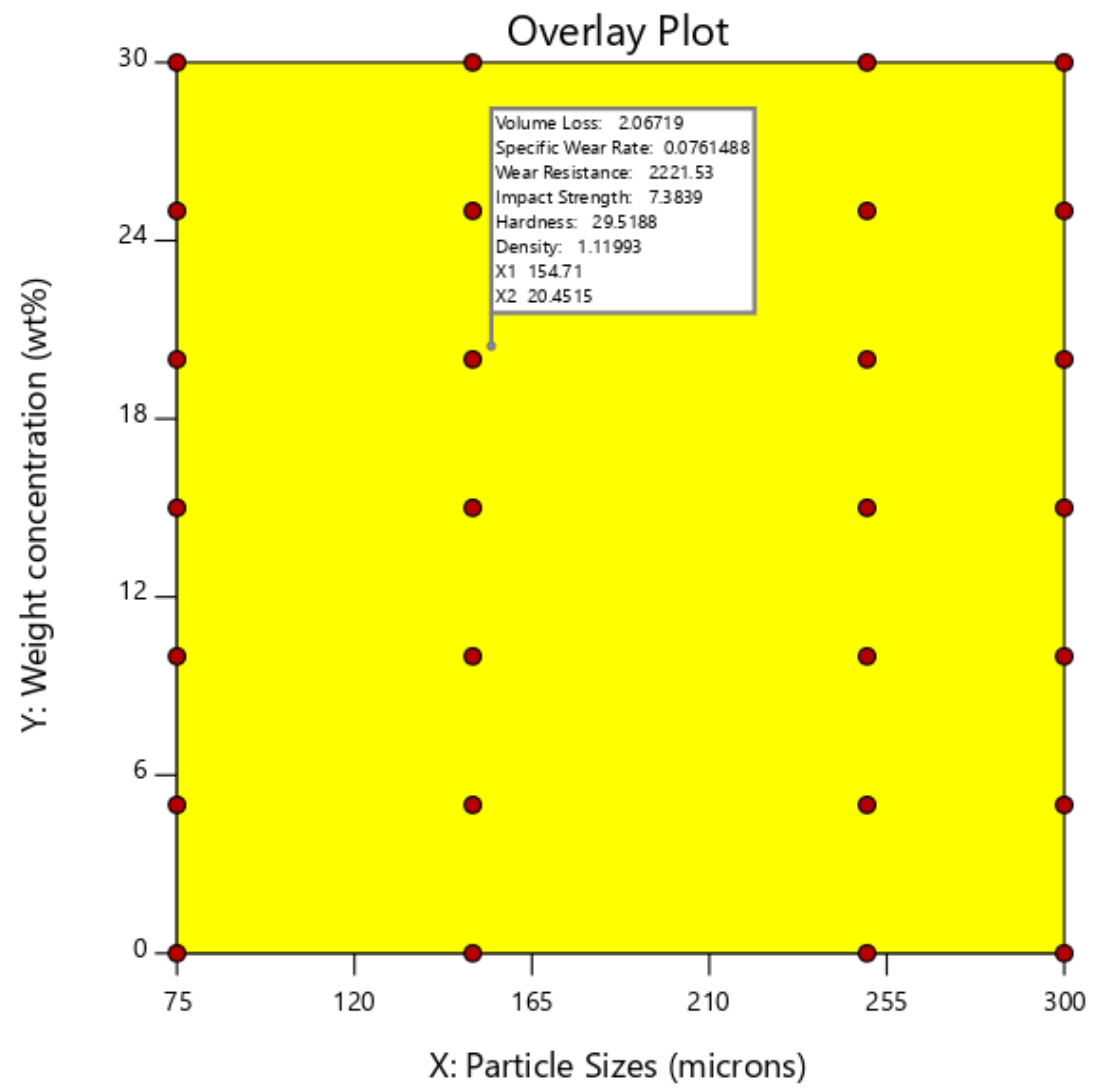

Fig 19. Overlay plot showing the graphical optimization solution.

Graphical optimization solution is used to produce something commonly referred to as an overlay graph. It is comprised of the contour plots from each response laid on top of each other. The numerical optimization target criteria are carried over and automatically initializes the graphical optimization criteria. Graphical optimization solution produces an overlay/contour plot in
Figure 19, which is a single plot highlighting the "sweet spot" where response criteria can be met. It is also used to show the limits of failure in a process. The contours are plotted at the limits specified by the criteria. One colour (bright yellow by default) defines the acceptable factor settings. Another colour (grey by default) defines the unacceptable factor settings. If intervals are 
included on the criteria, then a blend of the acceptable and unacceptable colours is used to show where the interval limits are unacceptable. The numerical optimization solutions (flags) are carried over and displayed if the graph is on the correct slice.

\section{CONCLUSIONS}

The foregoing report revealed the sucessful development of hardwood charcoal reinforced polyester matrix composite by the open mould technique. The composites exhibited better wear resistance at $5 \mathrm{wt} \%$ for all the reinforcement particle sizes examined than the unreinforced polyester. The SEM micrographs of the worn surface revealed a strong interfacial interaction and adhesion between the hardwood charcoal particles and the polyester matrix and progressive micro-ploughing and cutting as the sliding wear mechanism of the composite. RSM experimental design tool was effective in predicting and optimizing the responses of the dry sliding wear and the experimental density of the HWCP reinforced polyester matrix composites at a reinforcement particle size of $154.710 \mu \mathrm{m}$ and volume fraction of $20.451 \%$, under the considered test conditions. The optimally predicted and experimental properties are also in reasonable agreement.

\section{Acknowledgements}

The Authors appreciate the Tertiary Education Trust Fund (TETFund), Nigeria for financially supporting this research through the Institution Based Research (IBR) Interventions.

\section{REFERENCES}

[1] G. Agarwal, A. Patnaik, R.K. Sharma, Parametric Optimization and Three-Body Abrasive Wear Behavior of Sic Filled Chopped Glass Fiber Reinforced Epoxy Composites, International Journal of Composite Materials, vol. 3, no. 2, pp. 32-38, 2013, doi: 10.5923/j.cmaterials.20130302.02

[2] S.A. Bello, J.O. Agunsoye, J.A. Adebisi, N.K. Raji, S.B. Hassan, Wear Resistance Properties of Epoxy Aluminium Microparticle Composite, Proceedings on Engineering Sciences, vol. 1, no. 1, pp. 58-65, 2019, doi: 10.24874/PES01.01.007
[3] A.D. Moghadam, E. Omrani, P.L. Menezes, P.K. Rohatgi, Mechanical and tribological properties of self-lubricating metal matrix nanocomposites reinforced by carbon nanotubes (CNTs) and graphene - A review, Composites Part B: Engineering, vol. 77, pp. 402-420, 2015, doi: 10.1016/j.compositesb.2015.03.014

[4] A.A. Adediran, K.K. Alaneme, I.O. Oladele, E.T. Akinlabi, Wear characteristics of aluminium matrix composites reinforced with Si-based refractory compounds derived from rice husks, Cogent Engineering, vol. 7, iss. 1, pp. 1-21, 2020, doi: $10.1080 / 23311916.2020 .1826634$

[5] R.T. Ashok Kumar, N. Mohan, C. Mahesha, Sliding Wear Characteristics of Fiber Reinforced Fillers Filled Polymer Based Composites: A Review, International Journal of Materials Science, vol. 10, no. 2, pp. 133-169, 2015.

[6] B.C. Wang, H. He, X.F. He, H.D. Chen, B. Huang, Wear resistance, oil resistance, morphology and vulcanization performances of ethylenevinyl acetate/acrylonitrile butadiene rubber composites, Express Polymymer Letters, vol. 13, no. 12, pp. 1088-1103, 2019, doi: 10.3144/expresspolymlett.2019.94

[7] G.R. Chavhan, L.N. Wankhade, Optimization of Test Parameters that Influence on Dry Sliding Wear Performance of Steel Embedded Glass/Epoxy Hybrid Composites by Using the Taguchi Approach, Tribology in Industry, vol. 42, no. 4, 2020, doi: 10.24874/ti.863.03.20.09

[8] F.C. Campbell, Structural Composite Materials, ASM International, 2010.

[9] A. Lakshumu Naidu, S. Kona, Experimental Study of the Mechanical Properties of Banana Fiber and Groundnut Shell Ash Reinforced Epoxy Hybrid Composite, International Journal of Engineering, vol. 31, no. 4, pp. 659-665, 2018.

[10] F. Mindivan, M. Goktas, A. Colak, Dry Wear Studies on Reduced Graphene Oxide Filled Composites, Proceedings on Engineering Sciences, vol. 1, no. 1, 2019, doi: 10.24874/PES01.01.089

[11] L. Nicolais, M. Meo, E. Milella, Composite Materials - A Vision for the Future, SpringerVerlag London, pp.129-167, 2011

[12] S. Bagherpour, Fibre Reinforced Polyester Composites, in Polyester Handbook, IntechOpen, pp. 135-166, 2012.

[13] R.A. Ibrahem, Friction and Wear Behaviour of Fibre/Particles Reinforced Polyester Composites, International Journal of Advanced Materials Research, vol. 2, no. 2, pp. 22-26, 2016.

[14] R.A. Ibrahim, Influence of Natural Fillers on Tribological and Mechanical Performance of 
Polyester Composites, International Journal of Advanced Materials Research, vol. 2, no. 2, pp. 27-32, 2016.

[15] A. James, M.B. Davanageri, H. Rangaswamy, B.K. Chacko, D.M. Shanthappa, R. Kumar, D.S. Akkunji, The study of wear behaviour of glass/epoxy composites reinforced with titanium dioxide and graphite filler materials, AIP Conference Proceedings, vol. 2080, pp. 1-10, 2019, doi: $10.1063 / 1.5092894$

[16] S.B. Hassan, V.S. Aigbodion, S.N. Patrick, Development of Polyester/Eggshell Particulate Composites, Tribology in Industry, vol. 34, no. 4, pp. 217-225, 2012.

[17] B. Aldousiri, A. Shalwan, C.W. Chin, A review on tribological behaviour of natural reinforced composites, Journal of Reinforced Plastics and Composites, vol. 37, iss. 5, pp. 349-353, 2018, doi: $10.1177 / 0731684417747742$

[18] K. Friedrich, Z. Zhang, A.K. Schlarb, Effects of various fillers on the sliding wear of polymer composites, Composites Science and Technology, vol. 65, iss. 15-16, pp. 2329-2343, 2005, doi: 10.1016/j.compscitech.2005.05.028

[19] R.A. Ibrahem, Effect of Date Palm Seeds on the Tribological Behaviour of Polyester Composites under Different Testing Conditions, Journal of Material Sciences \& Engineering, vol. 4, iss. 6, 2015, doi: 10.4172/2169-0022.1000206

[20] C. Aravind, S. Gopalakrishnan, N. Radhika, Investigating the Adhesive Wear Properties of Aluminum Hybrid Metal Matrix Composites at Elevated Temperatures Using RSM Technique, Tribology in Industry, vol. 41, no. 4, 2019, pp. 604-612, doi: 10.24874/ti.2019.41.04.12

[21] M. Sakthivei, S. Ramesh, Mechanical properties of natural fibre (Banana, Coir, Sisal) polymer composites, Science Park, vol. 1, iss. 1, pp. 1-6, 2013.

[22] H. Sumithra, B.S. Reddy, A review on tribological behaviour of natural reinforced composites, J. Reinf. Plast. Compos., vol. 37, iss. 5, pp. 349-353, 2018, doi: 10.1177/0731684417747742

[23] C.A. Babu, S.A. Kalam, P.R. Kumar, Experimental and Analysis of Polyester - Jute- Hemp Fiber Reinforced Composite, International Journal of Engineering Development and Research, vol. 5, iss. 4, pp. 217-224, 2017.

[24] C.E. Njoku, K.K. Alaneme, J.A. Omotoyinbo, M.O. Daramola, Natural Fibers as Viable Sources for the Development of Structural, Semi-Structural, and Technological Materials - A Review, Advanced Materials Letters, vol. 10, no. 10, pp. 682-694, 2019, doi: 10.5185/amlett.2019.9907
[25] R.E. Njoku, A.E. Okon, T.C. Ikpaki, Effects of Variation of Particle Size And Weight Fraction on The Tensile Strength And Modulus of Periwinkle Shell Reinforced Polyester Composite, Nigerian Journal of Technology, vol. 30, no. 2, pp. 87-93, 2011.

[26] T. Khan, M.T.H. Sultan, A.H. Ariffin, The challenges of natural fiber in manufacturing, material selection, and technology application: A review, Journal of Reinforced Plastics and Composites, vol. 37, iss. 11, pp. 770-779, 2018, doi: $10.1177 / 0731684418756762$

[27] F. do Carmo Amorim, J.F.B. de Souza, J.M.L. dos Reis, The Quasi-static and Dynamic Mechanical Behavior of Epoxy Matrix Composites Reinforced with Curaua Fibers, Materials Research, vol. 21, no. 3, pp. 1-6, 2018, doi: 10.1590/1980-5373MR-2017-0828

[28] N. Venkateshwaran, A. ElayaPerumal, A. Alavudeen, M. Thiruchitrambalam, Mechanical and water absorption behaviour of banana/sisal reinforced hybrid composites, Materials \& Design, vol. 32, iss. 7, pp. 4017-4021, 2011, doi: 10.1016/j.matdes.2011.03.002

[29] H.B. Vinay, H.K. Govindaraju, P. Banakar, Evaluation of Glass/Carbon Reinforced Polymer Composites, Polymers and Polymer Composites, vol. 24, no. 7, pp. 469-472, 2016, doi: $10.1177 / 096739111602400704$

[30] K.K. Alaneme, S.R. Oke, J.A. Omotoyinbo, Water absorption characteristics of polyester matrix composites reinforced with oil palm ash and oil palm fibre, Usak University Journal of Material Sciences, vol. 2, pp. 109-120, 2013, doi: 10.12748/uujms.201324253

[31] S. Li, D. Li, Electrically conductive charcoal powder/ultrahigh molecular weight polyethylene composites, Materials Letters, vol. 137, pp. 409412, 2014, doi: 10.1016/j.matlet.2014.09.022

[32] S. Li, X. Li, Q. Deng, D. Li, Three kinds of charcoal powder reinforced ultra-high molecular weight polyethylene composites with excellent mechanical and electrical properties, Materials \& Design, vol. 85, pp. 54-59, 2015, doi: 10.1016/j.matdes.2015.06.163

[33] X. Li, B. Lei, Z. Lin, L. Huang, S. Tan, X. Cai, The utilization of bamboo charcoal enhances wood plastic composites with excellent mechanical and thermal properties, Materials \& Design, vol. 53, pp. 419-424, 2014, doi: 10.1016/j.matdes.2013.07.028

[34] N. Ayrilmis, J.H. Kwon, T.H. Han, A. Durmus, Effect of Wood-derived Charcoal Content on Properties of Wood Plastic Composites, Materials Research, vol. 18, no. 3, pp. 654-659, 2015, doi: 10.1590/1516-1439.001515 
[35] C.I. Madueke, B. Bolasodun, R. Umunakwe, J.N. Nwonah, Comparison of the Mechanical Properties of Charcoal Unsaturated Polyester Matrix Composite and Snail shell Unsaturated Polyester Matrix Composite, International Journal of Scientific and Engineering Research, vol. 5, no. 11, pp. 208-213, 2014.

[36] Q. Zhang, M. Usman, X. Lin, H. Cai, H. Lei, Temperature varied biochar as a reinforcing filler for high-density polyethylene composites, Composites Part B: Engineering, vol. 175, pp. 1-7, 2019, doi: 10.1016/j.compositesb.2019.107151

[37] M.I.M. Kandar, H.M. Akil, Application of Design of Experiment (DoE) for Parameters Optimization in Compression Moulding for Flax Reinforced Biocomposites, Procedia Chemistry, vol. 19, pp. 433-440, 2016, doi: 10.1016/j.proche.2016.03.035

[38] F.O. Edoziuno, R.O. Akaluzia, B.U. Odoni, S. Edibo, Experimental Study on Tribological (Dry Sliding Wear) Behaviour of Polyester Matrix Hybrid Composite Reinforced With Particulate Wood Charcoal and Periwinkle Shell, Journal of King Saud University - Engineering Sciences, vol. 33, iss. 5, 2021, doi: 10.1016/j.jksues.2020.05.007

[39] N.H. Mostafa, Z.N. Ismarrubie, S.M. Sapuan, M.T.H. Sultan, The influence of equi-biaxially fabric prestressing on the flexural performance of woven E-glass/polyester-reinforced composites, Journal of Composite Materials, vol. 50, iss. 24, pp. 3385-3393, 2015, doi: $10.1177 / 0021998315620478$

[40] C.R. Kothari, G. Garg, Research Methodology: Methods and Techniques, New Delhi: New Age International Pvl Ltd., Publishers, pp.129-344, 2014.

[41] F.O. Edoziuno, A.A. Adediran, B.U. Odoni, A.D. Akinwekomi, O.S. Adesina, M. Oki, Optimization and development of predictive models for the corrosion inhibition of mild steel in sulphuric acid by methyl-5-benzoyl- 2-benzimidazole carbamate (mebendazole), Cogent Engineering, vol. 7, iss. 1, pp. 1-19, 2020, doi: $10.1080 / 23311916.2020 .1714100$

[42] I.Y. Mohammed, Y.A. Abakr, S. Yusup, F.K. Kazi, Valorization of Napier grass via intermediate pyrolysis: Optimization using response surface methodology and pyrolysis products characterization, J. Clean. Prod., vol.142, no.4, pp..1848-1866, 2017, doi: 10.1016/j.jclepro.2016.11.099

[43] O.S. Fatoba, O.S. Adesina, G.A. Farotade, A.A. Adediran, Modelling and Optimization of Laser Alloyed AISI 422 Stainless Steel Using Taguchi Approach and Response Surface Model (RSM), Current Journal of Applied Science and Technology, vol. 23, iss. 3, pp. 1-16, 2017, doi: 10.9734/CJAST/2017/24512

[44] R.O. Akaluzia, F.O. Edoziuno, A.A. Adediran, B.U. Odoni, S. Edibo, and T.M. A. Olayanju, Evaluation of the effect of reinforcement particle sizes on the impact and hardness properties of hardwood charcoal particulate-polyester resin composites, Mater. Today Proc., vol. 38, pp. 570-577, 2021, doi: 10.1016/j. matpr.2020.02.980

[45] 0.M. Ikumapayi, E. Akinlabi, S.A. Akinlabi, Characterization of high strength aluminium based surface matrix composite reinforced with low-cost PKSA fabricated by friction stir processing, Materials Research Express, vol. 6, iss. 10, 2019, doi: 10.1088/2053-1591/ab395b

[46] N.H. Mostafa, Z.N. Ismarrubie, S.M. Sapuan, M.T.H. Sultan, Effect of fabric biaxial prestress on the fatigue of woven E-glass/polyester composites, Materials \& Design, vol. 92, pp. 579-589, 2016, doi: 10.1016/j.matdes.2015.12.109 